\title{
Construção de materiais formativos digitais inclusivos: desafios e possibilidades
}

\author{
Construction of inclusive digital training \\ materials: challenges and possibilities
}

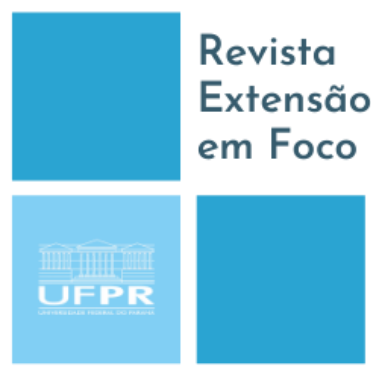

ISSN $2358-7180$

\section{Gabrieli Kmiecik ${ }^{1}$, Mikaely P. dos Santos ${ }^{2}$, Eduarda P. S. da Cruz ${ }^{3}$, Karianny Aparecida Gerotto del Mouro ${ }^{4}$, Ana Carina Stelko-Pereira ${ }^{5}$, Loriane Trombini Frick ${ }^{6}$}

\author{
RESUMO
}

Este trabalho tem por objetivo relatar o processo de construção de materiais multimidiáticos inclusivos, em formato de vídeos e art post, destinados à formação docente. Estas ações são desenvolvidas em dois projetos de extensão que fazem parte do Observatório do Clima Institucional e Prevenção da Violência em Contextos Educacionais. A partir da reestruturação dos projetos, em função da pandemia de coronavírus, identificou-se a necessidade de criar materiais multimidiáticos e que estes fossem inclusivos. No texto, são descritos os tipos de materiais produzidos, os meios empregados para torná-los inclusivos e os produtos derivados deste processo, como o Manual de Art Post e o Manual de Editoração de Vídeos, que se tornaram base para a produção de materiais futuros para todo o grupo. Destacam-se as possibilidades e os desafios encontrados, como a inserção da Audiodescrição nos materiais. Sugere-se que todos os outros projetos de extensão tenham a inclusão como meta, planejando-se a inclusão da interpretação em Libras - Língua Brasileira de Sinais e Audiodescrição como elementos essenciais das atividades extensionistas.

Palavras-chave: Inclusão. Materiais digitais. Audiodescrição. Libras. Extensão.

\section{ABSTRACT}

This work aims to describe building inclusive multimedia materials, in video and art post format, destined for teacher training. We developed these actions in two extension projects that are part of Observatory of Institutional Climate and Violence Prevention in Educational Contexts. Due to the restructuring of the projects due to the coronavirus pandemic, we identified the need to create inclusive multimedia materials. The text describes the type of materials produced, the means used to make them inclusive, and the products derived from this process, such as the Art Post Manual and the Video Editing Manual, which became the basis for producing future materials for the whole group. The possibilities and challenges encountered are highlighted, such as the insertion of audio descriptions in the materials.

\footnotetext{
${ }^{1}$ Graduanda do Curso de Matemática. Universidade Federal do Paraná (UFPR), Curitiba, Paraná, Brasil. E-mail: gabi.kmiecik@hotmail.com. Orcid: https://orcid.org/0000-0001-8002-2784

${ }^{2}$ Graduanda do Curso de História, Memória e Imagem. Universidade Federal do Paraná (UFPR), Curitiba, Paraná, Brasil. E-mail: mikapsantos21@gmail.com. Orcid: https://orcid.org/0000-0002-8871-0263

${ }^{3}$ Graduanda do Curso de Licenciatura em Música. Universidade Federal do Paraná (UFPR), Curitiba, Paraná, Brasil. E-mail: eduarda.santos.musica@gmail.com. Orcid: https://orcid.org/0000-0003-2304-3591 ${ }^{4}$ Mestranda em Educação em Ciências e em Matemática (UFPR). Intérprete de Libras no Instituto Federal do Paraná, Campus Assis Chateaubriand (IFPR), Assis Chateaubriand, Paraná, Brasil. E-mail: kariannygerotto@gmail.com. Orcid: https://orcid.org/0000-0003-1703-0508

${ }^{5}$ Doutora em Psicologia pela UFSCar. Professora Adjunta na Universidade Federal do Paraná (UFPR), Curitiba, Paraná, Brasil. E-mail: anastelko@gmail.com. Orcid: https://orcid.org/0000-0002-8089-132X

${ }^{6}$ Doutora em Educação pela UNESP. Professora Adjunta na Universidade Federal do Paraná (UFPR), Curitiba, Paraná, Brasil. E-mail: loriane.trombini.frick@ufpr.br. Orcid: https://orcid.org/0000-0002-41514329
} 
We suggest that all other extension projects have inclusion as a goal, planning the inclusion of Libras Brazilian Sign Language and audio description as essential elements of extension activities.

Keywords: Inclusion. Digital Materials. Audio description. Brazilian Sign Language. Extension.

\section{INTRODUÇÃO}

No contexto de pandemia causada pelo coronavírus (WORLD HEALTH ORGANIZATION, 2020), muitas atividades antes realizadas de forma presencial precisaram ser repensadas. Incluindo as atividades extensionistas. Muito do material construído para ser disponibilizado aos docentes de forma presencial, passou para o meio digital. Professores também passaram a buscar mais o meio digital para formar-se e aprimorar habilidades necessárias para enfrentar o ensino remoto emergencial, imposto com a necessidade do fechamento das escolas durante a pandemia. Logo, pensar estes materiais, tanto em relação ao conteúdo, quanto ao seu formato, tornou-se um desafio. Contratempo ainda mais árduo quando pensamos na necessidade da produção de materiais/recursos digitais inclusivos.

A inclusão social pode ser compreendida como uma proposta que busca a participação de todos, em especial daqueles que sempre foram considerados 'doentes' e incapazes frente aos padrões impostos por uma sociedade normativa. No Brasil, o movimento de inclusão ganhou um destaque na publicação da Lei 13.146/2015 (BRASIL, 2015) que apresenta muitos avanços em relação às condições das pessoas com deficiência no âmbito social. Compreende-se que a inclusão é um processo gradual e dinâmico que pode tomar distintas formas de acordo com as necessidades e habilidades dos sujeitos envolvidos (DÍAZ; BORDAS; GALVÃO; MIRANDA, 2009). Reconhecer a importância da inclusão é fazer como que todos sejam compreendidos de acordo com suas necessidades, sem discriminação.

Dessa forma, é preciso repensar os métodos de ensino e a organização escolar para atender a todos os alunos, sem distinção, como especifica a Política Nacional de Educação Especial na Perspectiva da Educação Inclusiva (BRASIL, 2008). Para que a inclusão seja atingida em sua forma plena, é necessário contar com recursos como as Tecnologias da Informação e Comunicação (TIC), como, por exemplo, os livros adaptados e o uso de músicas adaptadas em SPC (Sistemas Pictográficos de Comunicação) durante a aula (MOREIRA et al., 2020). Estas tecnologias possibilitam a realização de “[...] práticas educativas inovadoras através de uma pedagogia ativa e inclusiva, os alunos podem 
partilhar conhecimentos e experiências, estimulando, assim, uma aprendizagem cooperativa e grupal" (Ibid., p. 52). Sobre os meios digitais, Monteiro (2014) discorre sobre a falta de acesso às tecnologias, também chamada de digital gap. Em seu artigo, a autora defende o uso das TIC's como meio de inclusão e o uso delas no ambiente pedagógico. Segundo a autora, "Os meios tecnológicos facilitam a diversificação dos meios auditivos e visuais, bem como a sua difusão através de um discurso pedagógico que respeita e valoriza a multiculturalidade, contribuindo, portanto, para reduzir a lacuna digital, no que diz respeito ao acesso e à participação" (MONTEIRO, 2014, p. 4).

Apoiando-se nesses estudos e considerando o contexto social da pandemia, revelouse a necessidade da criação de materiais audiovisuais digitais inclusivos, não apenas para os alunos, mas voltados também à formação dos docentes. Cruz et. al. (2011) destacam a falta de formação adequada dos professores no que se refere a contextos educacionais inclusivos e apontam a necessidade de formação profissional adequada. "Neste sentido, os debates acadêmicos, que dão suporte aos professores inseridos na Educação Básica, precisam ser aprimorados e devem estar mais próximos das questões vivenciadas no dia a dia de intervenções profissionais relacionadas a pessoas que apresentam necessidades especiais" (CRUZ et al., 2011, p. 2).

A Política Nacional de Educação Especial na Perspectiva da Educação Inclusiva também especifica o papel do docente para a educação inclusiva:

Para atuar na educação especial, o professor deve ter como base da sua formação, inicial e continuada, conhecimentos gerais para o exercício da docência e conhecimentos específicos da área. Essa formação possibilita a sua atuação no atendimento educacional especializado e deve aprofundar o caráter interativo e interdisciplinar da atuação nas salas comuns do ensino regular, nas salas de recursos, nos centros de atendimento educacional especializado, nos núcleos de acessibilidade das instituições de educação superior, nas classes hospitalares e nos ambientes domiciliares, para a oferta dos serviços e recursos de educação especial. (BRASIL, 2008, p. 17-18)

Moreira et al. (2020) reiteram a contribuição da formação docente continuada e também o compartilhamento de conhecimento e experiência para a inclusão em ambientes escolares. Os autores sugerem a inserção de uma disciplina na formação docente que aborde a Comunicação Aumentativa e Alternativa (CAA) e também a conversa entre o Ensino Regular e o Ensino Especial para que a inclusão seja plena. Sobre o papel docente na inclusão, Cruz et al. (2011, p. 240) vão além colocando “os profissionais da Educação 
Básica na condição de autores de intervenções educacionais capazes de contribuir no enfrentamento dos desafios impostos por um cenário educacional inclusivo".

O eMAG - Modelo de Acessibilidade em Governo Eletrônico (DEPARTAMENTO DE GOVERNO ELETRÔNICO, 2014) é um documento que normatiza os conteúdos digitais do Governo Federal para que sejam inclusivos. Neste documento são observadas todas as legislações que discorrem sobre a inclusão e que asseguram os direitos das pessoas com deficiência. Algumas das recomendações para garantir a acessibilidade são: disponibilizar a navegação do site pelo teclado, a descrição de links que estejam na página da web e sempre que possível oferecer a descrição da imagem contida na página. Sobre o design e apresentação dos sites, o e-MAG detalha quais são as cores e o contraste mais acessível - e conta com tabelas de contraste entre cores para melhor ilustrar essa orientação. No que diz respeito à multimídia, como vídeos e áudios, a alternativa inclusiva é sempre disponibilizar descrição do vídeo ou áudio em texto, além da tradução em Língua Brasileira de Sinais - LIBRAS.

Pelo exposto, depreende-se que embora existam textos científicos e documentos oficiais sobre a adequação de materiais para que sejam inclusivos, a realidade ainda não condiz com a literatura. Por isso, o objetivo deste trabalho é relatar o processo de construção de material multimidiático (em formato de vídeos e art post) inclusivos, destinados à formação docente. Trata-se de um estudo descritivo, que visa apresentar o processo de construção dos materiais digitais inclusivos, a fim de inspirar outros projetos de extensão que também desenvolvem este tipo de material.

As ações relatadas estão sendo desenvolvidas no Observatório do Clima Institucional e Prevenção da Violência em Contextos Educacionais ${ }^{1}$, o qual tem por objetivo coordenar iniciativas de pesquisa e extensão, destinadas à promoção de relações interpessoais positivas, bem-estar, desenvolvimento socioemocional e acadêmico dos estudantes e profissionais em espaços educativos formais e não formais. A produção de material multimidiático instrucional e formativo para docentes, está atrelado a dois projetos de extensão que fazem parte do Observatório: "Convivência Ética" e "Violência Nota Zero".

Como dito, o contexto de pandemia exigiu que as atividades realizadas nos referidos projetos fossem reconstruídas. O momento exigia que novas formas de promover a interação dialógica com o público-alvo (docentes, estudantes e outros membros da comunidade educativa) fossem repensadas. Por isso, estes projetos uniram forças e 
traçaram um objetivo comum: identificar necessidades formativas docentes relacionadas às demandas pedagógicas e psicossociais de professores de Ensino Médio e Ensino Superior.

Por meio de pesquisa realizada de forma online com cerca de 120 professores de diversas regiões do país, realizada entre os meses de junho e julho de 2020, foi possível identificar os temas a serem trabalhados nos materiais formativos: metodologias ativas, relações interpessoais, cuidado de si e do outro, comunicação, gestão do tempo e autoeficácia. Além da coordenação dos projetos, a equipe de trabalho é composta por professores e técnicos especialistas nas áreas temáticas (da universidade e externos) e por estudantes de diversas áreas, como Pedagogia, Psicologia, Filosofia, Matemática, Medicina, História: memória e imagem, Música, Farmácia, Terapia Ocupacional, Comunicação e Ciências Biológicas, o que garante a interdisciplinaridade das ações.

Nesse sentido, este texto está organizado de forma a discorrer inicialmente sobre o tipo de material a ser produzido e, em seguida, sobre a indicação das frentes de trabalho realizadas para produzir material inclusivo, com estudos realizados e desafios enfrentados.

\section{RESULTADOS E DISCUSSÃO}

Após a seleção dos estudantes para o desenvolvimento destas ações, em especial, os mesmos passaram a reunir-se semanalmente no grande grupo, com as coordenadoras dos projetos. Na seleção, estes estudantes precisaram demonstrar, via prova prática, habilidades de editoração de vídeos (com uso de softwares específicos) e de criação de roteiros.

O material a ser produzido consistiu em duas art post e um vídeo por tema, totalizando 12 art post e seis vídeos. O processo de elaboração destes materiais, envolveu diversos fatores e procedimentos. Inicialmente, foi preciso deliberar no grupo sobre a Identidade Visual dos materiais, a qual estava atrelada à própria identidade do Observatório. Durante o processo de estudo da persona (características do público-alvo), retomada dos objetivos dos projetos e observatório, escolha de paleta de cores, famílias de fontes, tipo de imagens a serem usadas, linguagem (propositiva ou informativa), entre outras, suscitaram questões relacionadas à inclusão, como a adoção da linguagem não 
binária e a acessibilidade por pessoas surdas, com baixa visão ou outros problemas, como o daltonismo.

Neste momento, parte dos estudantes foi designada para a equipe "inclusão", justamente para estudar e pensar em como responder às demandas e dúvidas que surgiram. Este grupo realizou encontros de estudo com uma parceira do Observatório, professora e profissional Intérprete de Libras - Língua Brasileira de Sinais.

O grupo apresentou, então, um "piloto" de uma das art post, para ser objeto de análise e possibilitar a verificação se os produtos que seriam produzidos, estariam acessíveis a qualquer pessoa. Essa arte-piloto foi enviada à professora especialista na área, que em reunião com a equipe de inclusão orientou para as correções necessárias.

Figura 01 - Art-post piloto de Autoeficácia

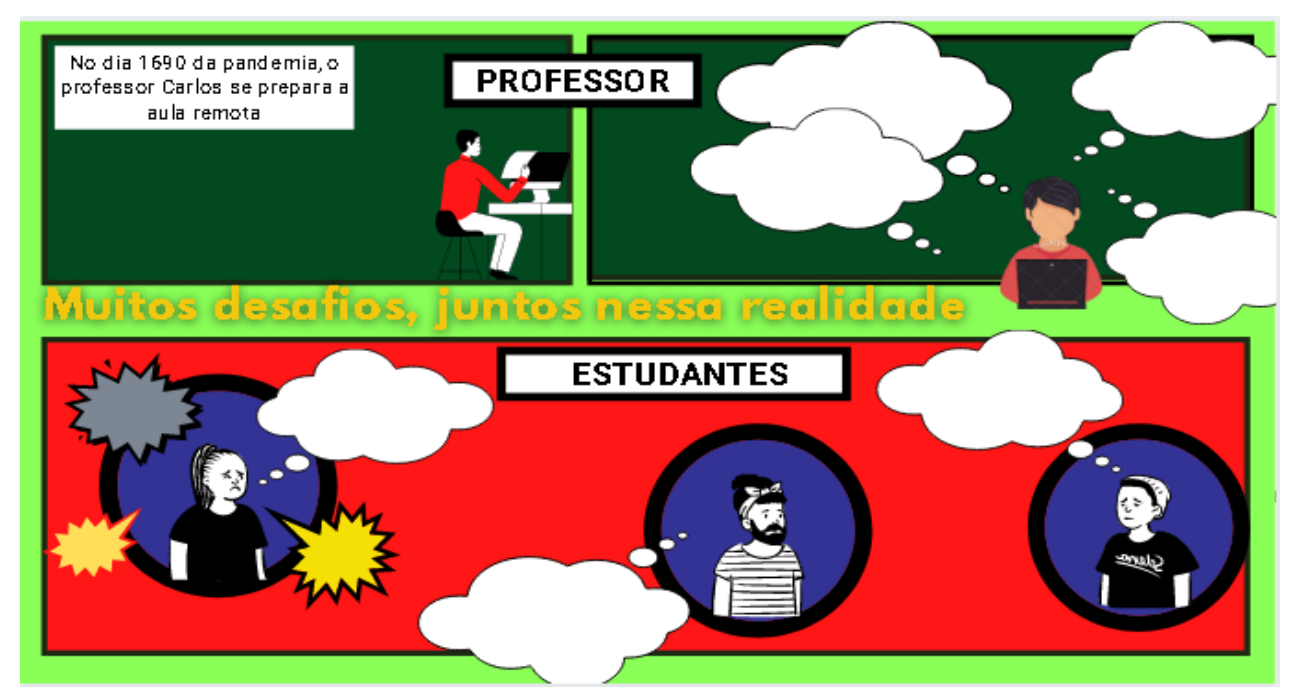

Fonte: Arquivo digital do Observatório do Clima Institucional e Prevenção da Violência em Contextos Educacionais (2020).

Na Figura 01 verifica-se a arte-piloto feita, relacionada ao tema Autoeficácia. A proposta da arte era lembrar uma história em quadrinhos, mostrando a visão do professor e seus pensamentos sobre a aula online e fazer um contraste com a visão dos alunos e os problemas que enfrentavam em casa e que os impedia de participar ativamente da aula. Observa-se, na imagem, que as cores, amarela e verde-claro, têm baixo contraste entre si, o que torna desconfortável a leitura, além de não ser adequada para pessoas daltônicas. A fonte escolhida também dificulta a leitura, por ser "desenhada" (não é totalmente preenchida). Os balõezinhos brancos com a escrita preta, embora comuns nas histórias 
em quadrinhos, tornam a leitura cansativa. Assim, ao analisar a ilustração e todos estes componentes, percebeu-se que uma pessoa com baixa visão ou daltonismo teria dificuldade de ler a mensagem presente.

A partir destes apontamentos, construiu-se uma nova proposta como pode-se observar na Figura 02, a seguir:

Figura 02 - Art-post Autoeficácia após estudo sobre apresentação gráfica

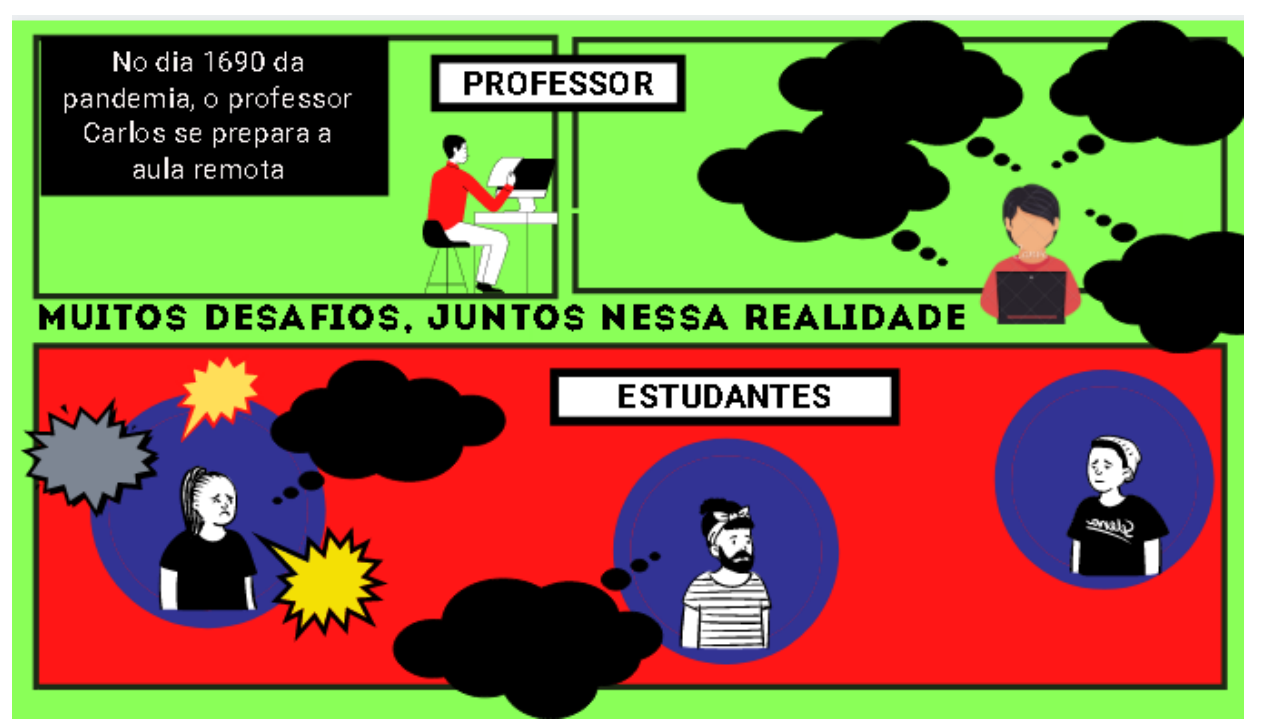

Fonte: Arquivo digital do Observatório do Clima Institucional e Prevenção da Violência em Contextos Educacionais (2020).

$\mathrm{Na}$ arte corrigida (Figura 02), por outro lado, percebe-se que as cores estão em contraste, o que a deixa harmoniosa e confortável de olhar. A nova fonte, com letras garrafais totalmente preenchidas e em uma cor de destaque com relação ao fundo da imagem, facilita a leitura por pessoas com baixa visão, daltônicas e pessoas com a visão normal. Nessa imagem, os balõezinhos são pretos e a escrita em branco fica destacada. Embora o balão escuro cause estranheza em um primeiro momento, percebemos que a leitura fica mais fácil e se torna menos cansativa aos olhos - tanto para pessoas com baixa visão e daltônicas, mas também para pessoas com a visão normal. A arte tornou-se, então, inclusiva.

O resultado destes encontros foi apresentado ao grande grupo e tais descobertas auxiliaram na escolha da paleta de cores e nas famílias de letras que fariam parte da Identidade Visual do Observatório. Estas e outras informações, foram então compiladas no Manual de Art Post e no Manual de Editoração de Vídeos. Inicialmente pensado como 
uma ferramenta para a unificação do processo de criação dos materiais, os manuais são fundamentais para centralizar os conhecimentos adquiridos no percurso a respeito da inclusão desses produtos. Assim, delineou-se sete diretrizes principais como guias para os membros atuais e futuros do Observatório:

1. Inversão do fundo: fundos escuros com letras claras facilitam a leitura. Exemplo: fundo preto com letra branca ou amarela.

2. Evitar letras pigmentadas e desenhadas: Optar por fontes que tenham letras que sejam sólidas, pois elas facilitam a leitura. No grupo, optou-se pelas fontes Cabin Sketch para títulos grandes e usada de forma totalmente preenchida; Intro Black Caps para título e texto (todos os tamanhos); e Just Another Hand como caracteres especiais e textos específicos, para demonstrar o efeito de escrita na lousa, como se fosse em giz.

3. Preferir escritas em preto ou branco: Mesmo que não seja feita a inversão do fundo, escritas em preto ou branco facilitam a leitura, principalmente para quem tem baixa visão ou daltonismo.

4. Evitar cores primárias uma sobre a outra: a leitura fica mais fácil quando não são usadas de forma sobreposta. Exemplo que deve ser evitado: verde e azul; verde e vermelho; vermelho e azul.

5. Cores primárias lado a lado: cores primárias lado a lado fornecem um bom contraste, que facilita a leitura.

6. Texto em só uma cor de fundo: se a imagem tiver mais de uma cor no fundo (por exemplo com formas coloridas), optar por encaixar o texto em apenas uma das cores.

7. Cores tom-sobre-tom: escrever em cima de um fundo de duas cores que são do mesmo tom (verde claro e verde escuro, por exemplo) não gera problema para a leitura.

A partir dessas compreensões e da definição da paleta de cores da identidade do projeto (Tradic), montamos as duas paletas mostradas nas Figuras 03 e 04 . A Figura 03 traz as cores definidas como base para o projeto e suas variações, do tom mais claro ao mais escuro. Elas estão presentes no fundo das art post, nos títulos, desenhos e outros elementos que compõem o conjunto visual. A Figura 04, por sua vez, mostra como essas cores são vistas por quem possui o daltonismo. Essa paleta auxilia, principalmente, na escolha de cores que não se confundam quando sobrepostas, para preservar o texto, desenho e outros elementos contidos na art post ou vídeo. 
Figura 03 - Paleta de cores da identidade do projeto

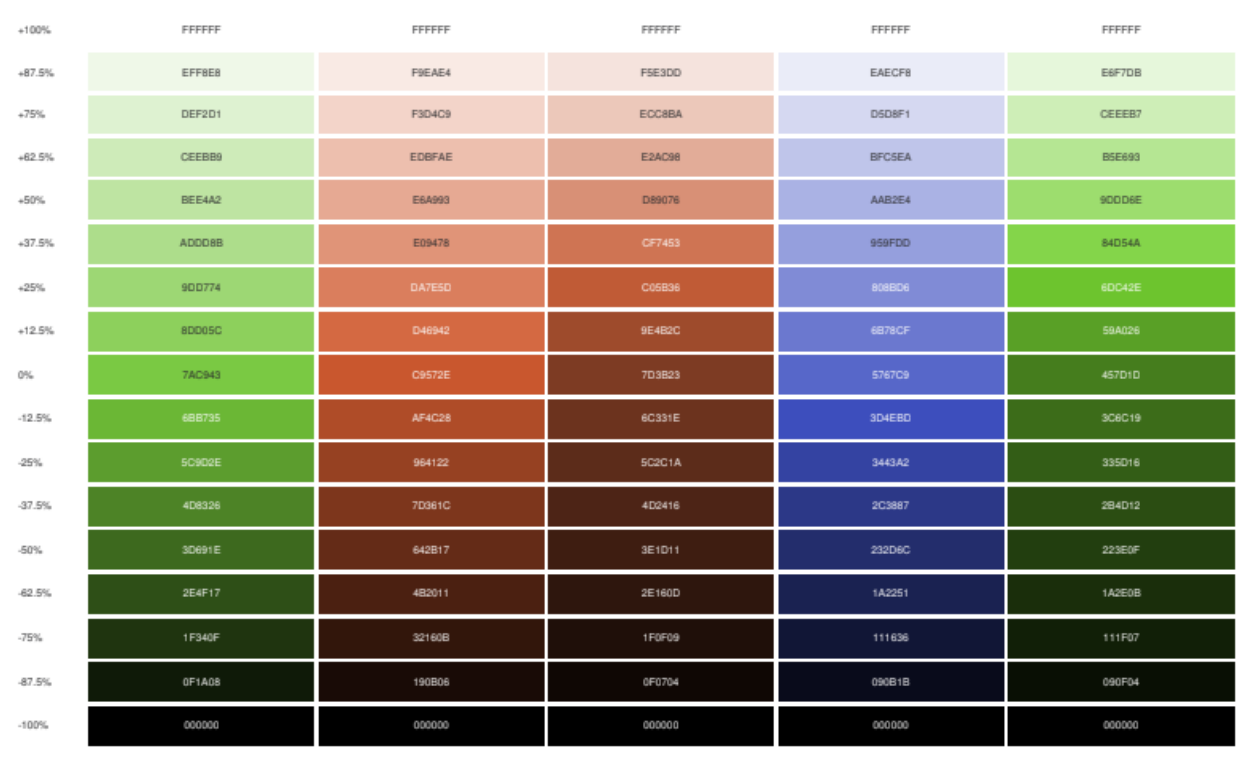

Fonte: Arquivo digital do Observatório do Clima Institucional e Prevenção da Violência em Contextos Educacionais (2020).

Figura 04 - Paleta que simula a visão daltônica das cores

\begin{tabular}{|c|c|c|c|c|c|}
\hline arginal & $7 \mathrm{Th}$ Cas & cassiat & тове2 & stencs & 457010 \\
\hline Probanopela & 909083 & s7aes? & Gosfas & soseder & SDSDS4 \\
\hline Protunamay & seatss & BA7cas & 7050208 & Saftice & AFanes \\
\hline Dofectranopia & 9796 B & geASSA & $64092 A$ & SOSBAB & sassag \\
\hline Decereranomey & mases & 827403 & efaceses & Stearese & 50652A \\
\hline Trtanopopas & T27002 & Casf44 & 792025 & streas & A7tseAA \\
\hline Thenemaly & reassa & Csacas & 703427 & 572187 & 466325 \\
\hline Achromanopesia & nensas & 747274 & АВAGAB & 606060 & 616161 \\
\hline Bechomatomay & areans & seanst & 624as9 & asenses & Stabut2 \\
\hline
\end{tabular}

Fonte: Arquivo digital do Observatório do Clima Institucional e Prevenção da Violência em Contextos Educacionais (2020).

As Figuras 05 e 06 ilustram partes de duas art post e a Figura 07 uma cena de um dos vídeos, nas quais é possível perceber a escolha das cores, letras, sobreposição de 
cores/elementos que compõem a imagem. Na Figura 05 podemos observar a arte inclusiva, na qual optou-se por um fundo em verde - que é uma das cores-identidade do projeto - e branco. A escrita em branco no fundo verde, para uma visualização confortável. O número '2' e o desenho em verde mais escuro no fundo branco, contribuem para a acessibilidade da imagem.

$\mathrm{Na}$ Figura 06 observa-se que o fundo tem duas cores, mas o texto está escrito ou na parte mais escura, ou na parte mais clara. Não foi escrito texto na divisão dessas cores, pois isso torna a leitura muito difícil e nada acessível. A Figura 07 é um quadro do vídeo de Metodologias Ativas e observa-se, assim como na Figura 06, que o texto não é escrito em partes nas quais há o encontro de cores do fundo. Nessa imagem também é possível ver a legenda destacada do fundo, pois a letra é clara, mas tem o contorno em verde.

Figura 05 - Art post Gestão de Tempo

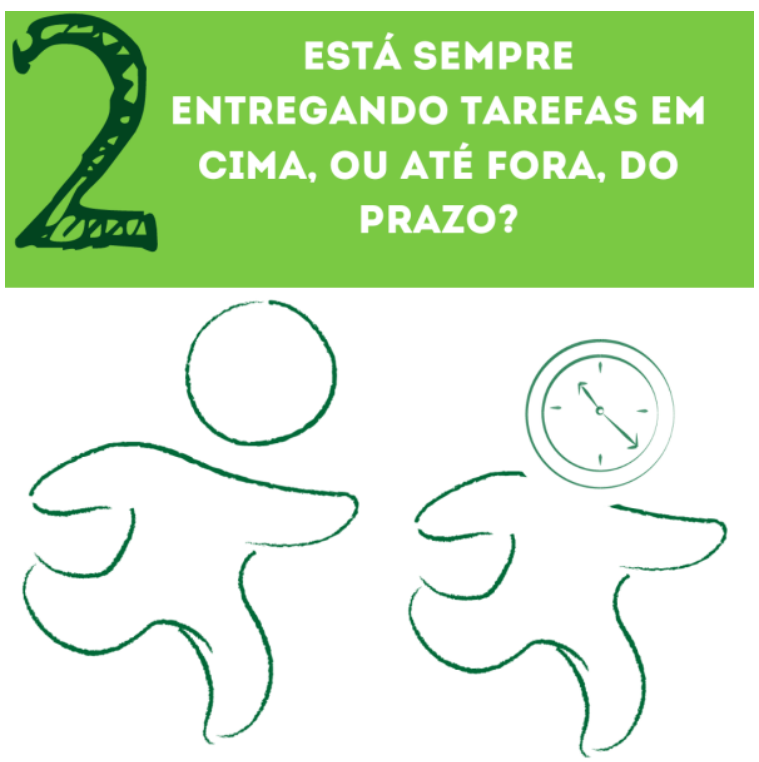

Fonte: Arquivo digital do Observatório do Clima Institucional e Prevenção da Violência em Contextos Educacionais (2020). 
Figura 06 - Art post Comunicação Não Violenta

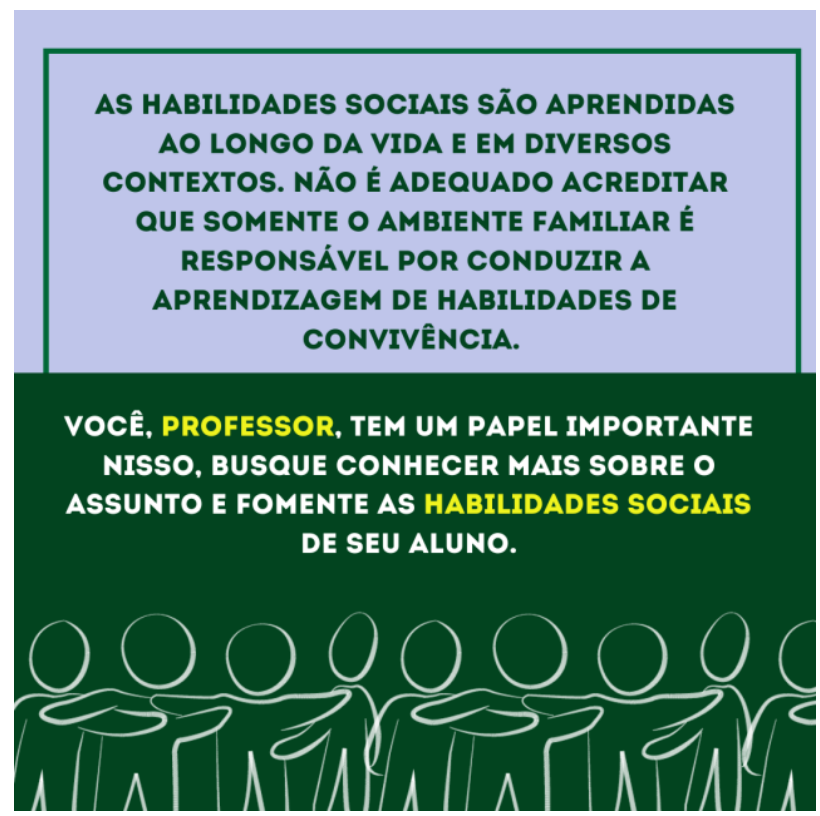

Fonte: Arquivo digital do Observatório do Clima Institucional e Prevenção da Violência em Contextos Educacionais (2020).

Figura 07 - Imagem do vídeo Metodologias Ativas

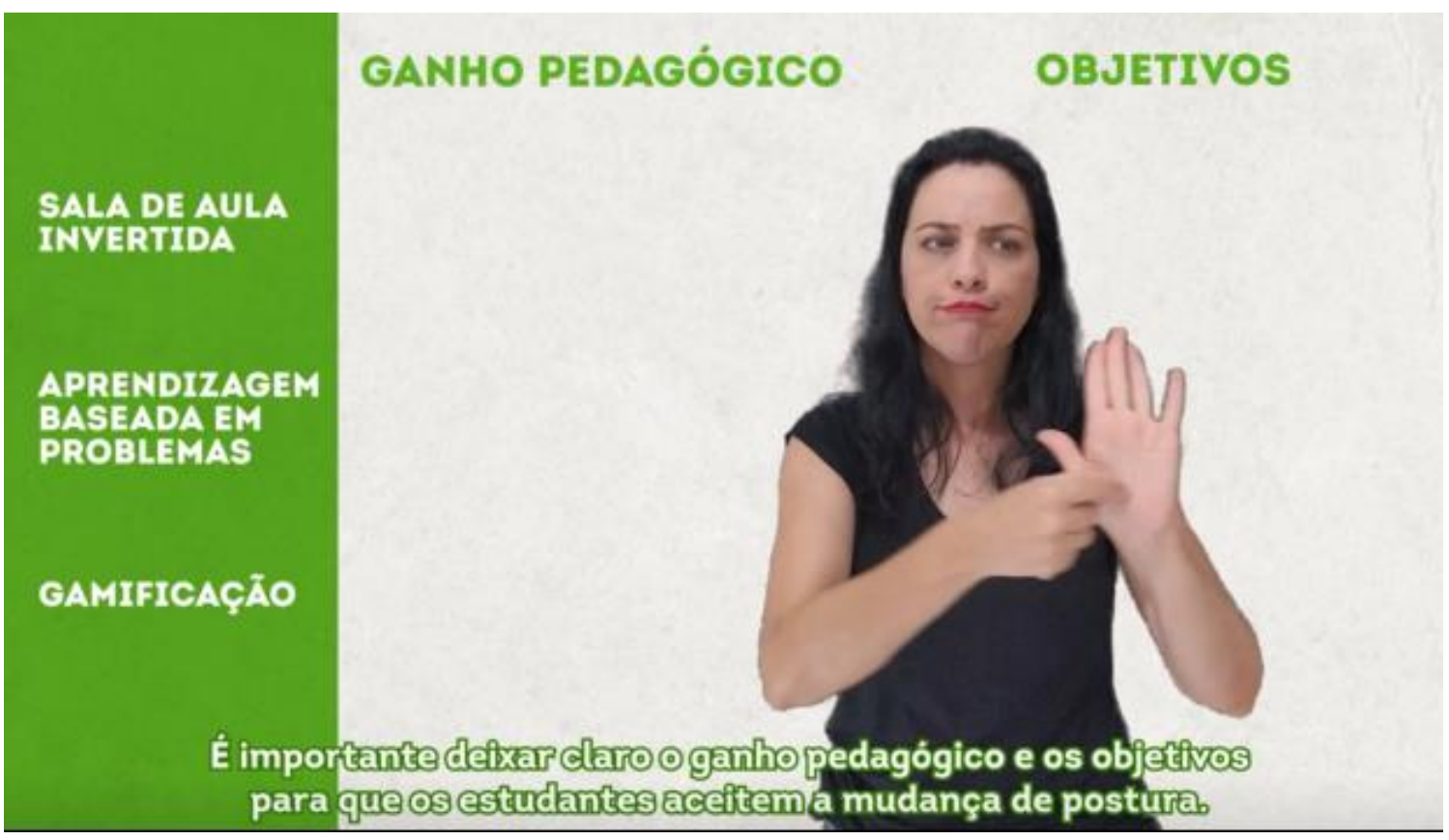

Fonte: Arquivo digital do Observatório do Clima Institucional e Prevenção da Violência em Contextos Educacionais (2020).

Como dito, outro aspecto relacionado à inclusão foi com relação à adoção da Linguagem Não-Binária (LN-B) no material produzido, em oposição ao uso exclusivo da 
linguagem neutra masculina ou binária (masculina e feminina). A Linguagem NãoBinária (LN-B) ou Neutra refere-se a uma comunicação de forma a não demarcar o gênero para as pessoas às quais o texto está escrito. Na LN-B são modificados os pronomes, substantivos, artigos e adjetivos, mas tendo em vista preservar o entendimento da frase pelo interlocutor. São quatro os sistemas gramaticais da Linguagem Não-Binária que são utilizados: o sistema El, sistema Ilu, sistema Elu e o uso da vogal 'e' no lugar das vogais 'o' ou 'a'. Ela é inclusiva à medida que se refere a todas as pessoas, inclusive aquelas que não se identificam com os gêneros binários (masculino ou feminino) e às pessoas trans (LAU; SANCHES, 2019). Para auxiliar o público-alvo na compreensão do que é a LNB, elaborou-se uma art post explicando seu significado e usos, conforme a Figura 08:

Figura 08 - Art post Linguagem Não-Binária
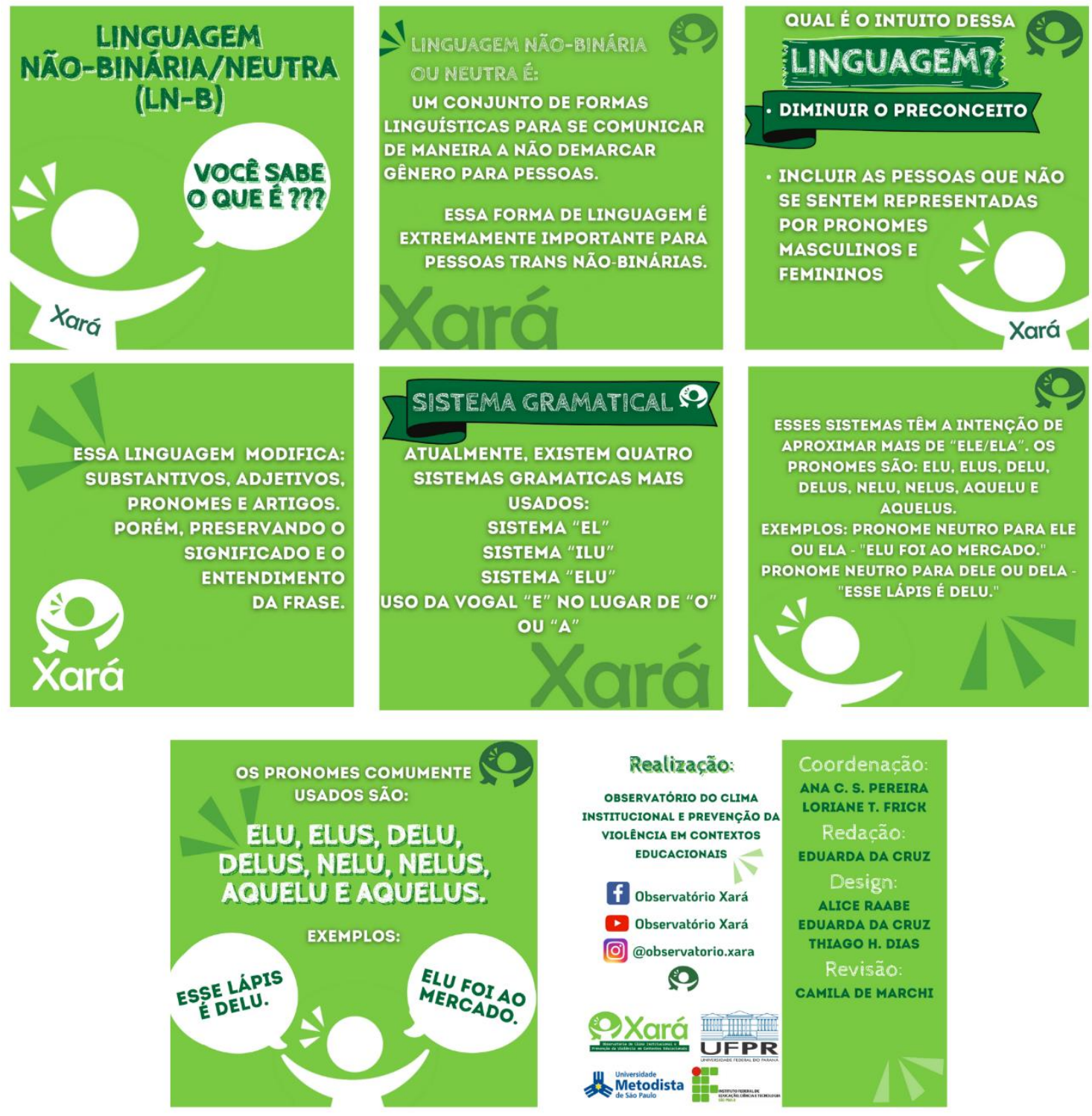
Fonte: Arquivo digital do Observatório do Clima Institucional e Prevenção da Violência em Contextos

Educacionais (2020).

Porém, não foi possível utilizar a Linguagem Não-Binária em todas as postagens do Observatório do Clima Institucional e Prevenção da Violência em Contextos Educacionais, pela defasagem de uma orientação normativa da instituição ao qual o Observatório está vinculado, que determina o uso de linguagem binária utilizando os pronomes, substantivos, artigos e adjetivos ou no masculino ou no feminino.

Para além destes aspectos, em especial com relação à elaboração de produtos em formato de vídeo, o grupo deliberou sobre o uso de legendas em português e a inserção da tradução da narração para a Língua Brasileira de Sinais. Destaca-se que isso só foi possível em função da participação de uma intérprete no grupo de trabalho, pois os profissionais da instituição não dispõem de carga horária específica para ajudar neste tipo de projeto. No momento de editar os vídeos, a equipe de editoração decidiu usar a imagem da intérprete como componente da linguagem narrativa da história, como pode ser observado na Figura 09.

Figura 09 - Vídeo Gestão de Tempo

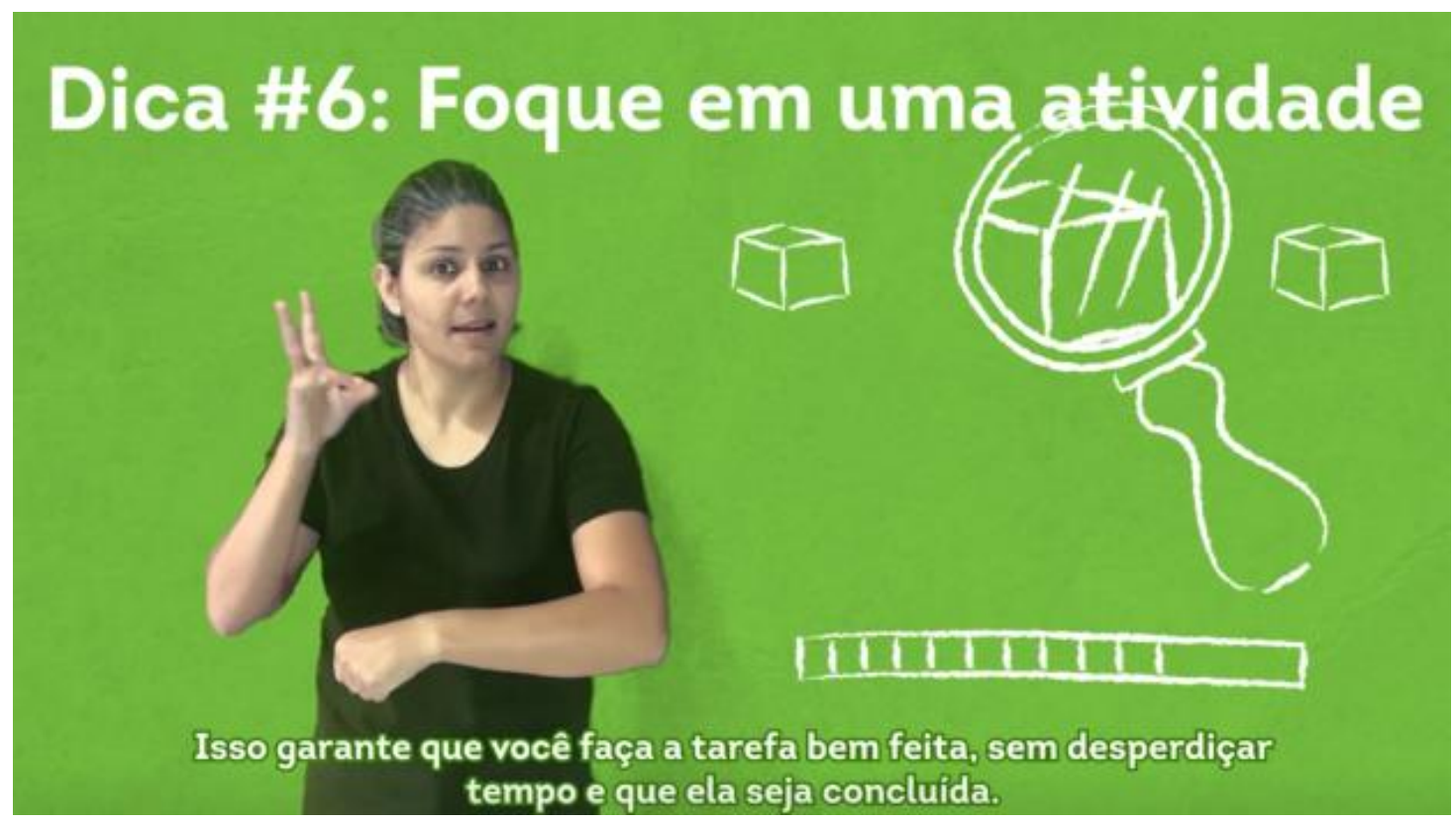

Fonte: Arquivo digital do Observatório do Clima Institucional e Prevenção da Violência em Contextos Educacionais (2020).

Por fim, a inclusão também está relacionada à acessibilidade aos materiais, ou seja, sua disponibilidade para uso e reprodução. Por isso, o grupo registrou as produções sob a 
Licença Creative commons CC BY-NC, ou seja, essa licença não permite o compartilhamento comercial, entretanto abre a possibilidade para mudanças, adaptações e compartilhamentos para fins não lucrativos, permite acima de tudo a atualização contínua entre profissionais que pretendam usar esses recursos como base para projetos futuros.

\section{CONSIDERAÇÕES FINAIS}

O objetivo deste texto foi relatar o processo de produção de materiais audiovisuais inclusivos no formato de art post e vídeos para serem divulgados em redes sociais pelos professores e alunos do Observatório do Clima Institucional e Prevenção da Violência em Contextos Educacionais. O processo relatado evidenciou as dificuldades encontradas pelos estudantes ao pensar e produzir o material audiovisual, mas também os produtos derivados deste processo, como o Manual de Art Post e o Manual de Editoração de Vídeos, que se tornaram base para a produção de materiais futuros para todo o grupo.

Depreende-se que a inclusão não é um processo internalizado nas práticas e relações sociais. Produzir materiais acessíveis para todos deveria ser a regra e não a exceção. Os desafios foram e são inúmeros, como encontrar manuais e cursos que orientem objetivamente a produção de materiais audiovisuais inclusivos - quais cores usar, o que não fazer -, a falta de recursos financeiros para incluir a Audiodescrição e para remunerar pessoas com deficiência que pudessem testar o material e auxiliar a classificá-lo como inclusivo ou não.

Sugere-se que todos os outros projetos de extensão tenham a inclusão como meta, planejando-se a inclusão da interpretação em Libras - Língua Brasileira de Sinais e Audiodescrição como elementos essenciais das atividades extensionistas. Compartilhar os desafios e conhecimentos construídos neste processo torna-se fundamental para tornar a sociedade realmente inclusiva. É preciso pensar sobre isso e os espaços de extensão e pesquisa são importantes para tal análise e reconstrução de posturas excludentes. Esperase que o processo aqui relatado possa auxiliar outras ações extensionistas.

\section{AGRADECIMENTOS}


Agradecemos a todas as instituições de fomento às ações extensionistas e que contribuíram financeiramente para a realização da produção destes materiais audiovisuais inclusivos. À Universidade Federal do Paraná que disponibiliza o recurso para os estudantes bolsistas do projeto via Edital PROIND; à Pró-Reitoria de Extensão e Cultura (PROEC) da UFPR e à Fundação Araucária que ofertaram editais de bolsas e recursos respectivamente.

Aos professores e técnicos que fazem parte desta iniciativa e aos alunos bolsistas e voluntários do projeto. Às intérpretes de Libras Karianny Aparecida Gerotto del Mouro e Fabíola Zappielo que fizeram a tradução dos vídeos para Libras.

\section{NOTAS}

1. O Observatório do Clima Institucional e Prevenção da Violência em Contextos Educacionais é uma ação desenvolvida na Universidade Federal do Paraná (UFPR) em parceria com o Instituto Federal de São Paulo - Campus Presidente Epitácio (IFSP - PEP) e a Universidade Metodista de São Paulo (UMESP). As ações podem ser encontradas em https://www.instagram.com/observatorio.xara/ .

\section{REFERÊNCIAS}

BRASIL. Lei no 13146, de 6 de julho de 2015. Institui a Lei Brasileira de Inclusão da Pessoa com Deficiência (Estatuto da Pessoa com Deficiência). Diário Oficial da União, Brasília, DF, 06 de julho de 2015. Disponível em: http://www.planalto.gov.br/ccivil_03/_ato2015-2018/2015/lei/113146.htm. Acesso em: 15 mar. 2021.

\section{BRASIL. Política Nacional de Educação Especial na Perspectiva da Educação} Inclusiva (Documento elaborado pelo Grupo de Trabalho nomeado pela portaria $n^{\circ}$ 555/2007, prorrogada pela Portaria n ${ }^{\circ}$ 948/2007, entregue ao Ministro da Educação em 07 de janeiro de 2008). Ministério da Educação. Brasília, 2008. Disponível em: http://portal.mec.gov.br/arquivos/pdf/politicaeducespecial.pdf. Acesso em: 15 mar. 2021.

CRUZ, G.; SCHNECKENBERG, M.; TASSA, K.; CHAVES, L. Formação continuada de professores inseridos em contextos educacionais inclusivos. Curitiba: UFPR, 2011. p. 229-243. Disponível em: https://www.scielo.br/pdf/er/n42/a15n42.pdf. Acesso em: 01 abr. 2021. 
CUEVAS, P.; GONÇALVES, V.; VALCÁRCEL, A.; MOREIRA, J. Inovação na educação com TIC: Livros de atas. Porto, Portugal: Universidade aberta. Outubro de 2020.

Disponível

em:

https://repositorio.ipcb.pt/bitstream/10400.11/7293/1/Atas_SPC_ieTIC2020.pdf. Acesso em: 01 abr. 2021.

DIAZ, F.; BORDAS, M.; GALVÃO, N.; MIRANDA, T. Educação inclusiva, deficiência e contexto social: questões contemporâneas. Salvador: EDUFBA, 2009.

DEPARTAMENTO DE GOVERNO ELETRÔNICO. eMAG: Modelo de Acessibilidade em Governo Eletrônico, 2014. Disponível em: http://emag.governoeletronico.gov.br/. Acesso em: 01 abr. 2021.

LAU, H. D.; SANCHES, G. J. A linguagem não-binária na língua portuguesa: possibilidades e reflexões making herstory. Revista X, v. 14, n. 4, p. 87, 2019. http://dx.doi.org/10.5380/rvx.v14i4.66071.

MONTEIRO, A. Mind the Digital Gap: ambientes digitais inclusivos como dispositivos pedagógicos. Rio de Janeiro: e-Mosaicos, 2014. p. 1-9. Disponível em: https://www.e-publicacoes.uerj.br/index.php/e-mosaicos/article/view/14352/12010.

Acesso em: 01 abr. 2021.

RAMALHETE, E.; GIL, H.; SOUSA, C. Recursos educativos digitais inclusivos em texto e canção: estudo exploratório com SPC. In: Conferência Ibérica de Inovação na Educação com TIC, VI, 2020, Porto: Editora, 2020. p. 52-66. Disponível em: https://repositorio.ipcb.pt/bitstream/10400.11/7293/1/Atas_SPC_ieTIC2020.pdf. Acesso em: 01 abr. 2021.

WORLD HEALTH ORGANIZATION. Coronavirus disease (COVID-19) pandemic. 2020. Disponível em: https://www.who.int/emergencies/diseases/novelcoronavirus-2019. Acesso em: 01 abri. 2021

Recebido em: 09 de abril de 2021. Aceito em: 20 de abril de 2021. 